\title{
Awareness on Bone Marrow Depressors Among Dental Students
}

\author{
A.Alagu Rathi Bharathi ${ }^{1}$, Dhanraj Ganapathy ${ }^{2}$, Subhashree $\mathrm{R}^{3}$ and Rakshagan ${ }^{4}$ \\ ${ }^{1}$ Saveetha Dental College and Hospitals Saveetha Institute of \\ Medical and Technical Sciences Saveetha University \\ ${ }^{2}$ Professor and Head of the Department of Prosthodontics Saveetha Dental College and Hospitals \\ Saveetha Institute of Medical and Technical Sciences Saveetha University Chennai 77, India \\ ${ }^{3}$ Senior Lecturer Department of Prosthodontics Saveetha Dental College and Hospitals Saveetha \\ Institute of Medical and Technical Sciences Saveetha University Chennai -77, India \\ ${ }^{4}$ Senior Lecturer Department of Prosthodontics Saveetha Dental College and Hospitals Saveetha \\ Institute of Medical and Technical Sciences Saveetha University Chennai -77, India
}

\section{ABSTRACT}

The aim of the study is to know the knowledge and awareness on the bone marrow depressors among the dental students Bone marrow suppression also known as myelotoxicity or myelosuppression, is the decrease in production of cells responsible for providing immunity (leukocytes), carrying oxygen (erythrocytes), and/or those responsible for normal blood clotting (thrombocytes). Bone marrow suppression is a serious side effect of chemotherapy and certain drugs affecting the immune system such as azathioprine. Non steroidal anti-inflammatory drugs (NSAIDs), in some rare instances, may also cause bone marrow suppression. The decrease in blood cell counts does not occur right at the start of chemotherapy because the drugs do not destroy the cells already in the bloodstream (these are not dividing rapidly). Instead, the drugs affect new blood cells that are being made by the bone marrow. The present study is an online based survey conducted among the dental students.The participants were from 1st, 2nd, 3rd, 4th and Intern years of BDS. Questionnaires were prepared and distributed among dental students through an online link from the survey planet. About $66.67 \%$ of the students were well aware that bone marrow depression can be caused by drugs. From the results of the survey it is clear that most of the dental students were well aware of bone marrow depressors and also had proper knowledge about the bone marrow depressions and its complications.

KEY WORDS: BONE MARROW DEPRESSORS, DRUGS , COMPLICATIONS, DENTAL STUDENTS.

\section{INTRODUCTION}

Bone marrow depression is a laboratory finding indicating decreased number of hematopoietic cells in the bone marrow. It may result from decreased proliferation of

\section{ARTICLE INFORMATION}

*Corresponding Author: dhanraj@saveetha.com

Received 15th June 2020 Accepted after revision 9th August 2020

Print ISSN: 0974-6455 Online ISSN: 2321-4007 CODEN: BBRCBA

Thomson Reuters ISI Web of Science Clarivate Analytics USA and Crossref Indexed Journal

\section{Clarivate}

crossef

NAAS Journal Score 2020 (4.31) SJIF: 2020 (7.728)

A Society of Science and Nature Publication,

Bhopal India 2020. All rights reserved.

Online Contents Available at: http//www.bbrc.in/

Doi: http://dx.doi.org/10.21786/bbrc/13.7/11 all or part of the hematopoietic series. Microscopically, the hematopoietic cells are replaced by adipocytes. Bone marrow suppression also known as myelotoxicity or myelosuppression, is the decrease in production of cells responsible for providing immunity (leukocytes), carrying oxygen (erythrocytes), and/or those responsible for normal blood clotting (thrombocytes). (Inman, 1977) (d'Onofrio and Zini, 2014) Bone marrow suppression is a serious side effect of chemotherapy and certain drugs affecting the immune system such as azathioprine. (Snow and Gibson, 1995) The risk is especially high in cytotoxic chemotherapy for leukemia. Non steroidal anti- 
inflammatory drugs (NSAIDs), in some rare instances, may also cause bone marrow suppression. (Graumlich, 2001) The decrease in blood cell counts does not occur right at the start of chemotherapy because the drugs do not destroy the cells already in the bloodstream (Weeks et al., 2012). Instead, the drugs affect new blood cells that are being made by the bone marrow.(Brown and Carbone, 1970) When myelosuppression is severe, it is called myeloablation.(Hirbe et al., 2007).

Many other drugs including common antibiotics may cause bone marrow suppression.(Langdon, Crook and Dantas, 2016) Unlike chemotherapy the effects may not be due to direct destruction of stem cells but the results may be equally serious. The treatment may mirror that of chemotherapy-induced myelosuppression or may be to change to an alternate drug or to temporarily suspend treatment. (Antman et al., 1988) (Friberg et al., 2002) Because the bone marrow is the manufacturing center of blood cells, the suppression of bone marrow activity causes a deficiency of blood cells.(Punjabi, Moore and Ralph, 1983) This condition can rapidly lead to life-threatening infection, as the body cannot produce leukocytes in response to invading bacteria and viruses, as well as leading to anaemia due to a lack of red blood cells and spontaneous severe bleeding due to deficiency of platelets. (Nicholson-Weller, Spicer and Austen, 1985).

Pain management is an everyday challenge in dentistry. Analgesics are the group of drugs prescribed for effective pain management, of which nonsteroidal anti-inflammatory drugs (NSAIDs) are drugs commonly prescribed in dental practice for the management of pain and swelling. Of these substances, paracetamol and ibuprofen are the most widely used (Poveda Roda et al., 2007). The non-selective inhibition of cyclooxygenase induced by the conventional NSAIDs induces a reduction in thromboxane A2 synthesis, which in turn leads to the inhibition of platelet aggregation - an important step in hemostasis . (Armijo et al., 1977). Previously our department has published extensive research on various aspects of prosthetic dentistry (Anbu et al. 2019; Ashok and Ganapathy 2019; Ganapathy et al. 2017; Jain 2017; Ariga et al. 2018; Evaluation of Corrosive Behavior of F...; Ranganathan et al. 2017; Jain 2017; Duraisamy et al. 2019; Gupta et al. 2018; Varghese et al. 2019), this vast research experience has inspired us to research about to research about the awareness on bone marrow depressors among dental students.

\section{MATERIAL AND METHODS}

The present study is an online based survey conducted among the dental students. The participants were from 1st, 2nd, 3rd, 4th and Intern years of BDS. Questionnaires were prepared and distributed among dental students through an online link from the survey planet. The total number of participants was 89 dental students. Participation in this study was voluntary. The questionnaire contained 15 questions. Independent variables were demographics such as year of study of participants. Dependent variables were bone marrow depressors, dental students . Only the completed surveys were included for analysis. The collected results were entered in Microsoft excel. Data analysis was done using SPSS software 20.0. Statistics used for analysis was Descriptive statistics and comparison of variables were done using chi square test where $\mathrm{p}<0.05$, statistically significant .

\section{RESULTS AND DISCUSSION}

Students from different years participated in the survey. The participants were from the first years (27.45) second years(25.49) third years(25.49) and fourth year(21.57) dental students (Figure 1). About 84.3\% of students are aware of the importance of the bone marrow functioning in our body and about $15.69 \%$ were not aware of the importance of the bone marrow functioning in our body. (Figure 2). About 68.63\% of students were aware of the conditioning called bone marrow depression and about $31.37 \%$ were not aware of the conditioning called the bone marrow depression. (Figure 3).

About $66.67 \%$ of the students were well aware that bone marrow depression can be caused by drugs and about $33.33 \%$ of the students were not aware that bone marrow depression can be caused by drugs.(Figure 4). About $52.94 \%$ of students were aware that the NSAID group of drugs may induce bone marrow suppression and about $47.06 \%$ of students were not aware that the NSAID group of drugs may induce bone marrow suppression (Figure 5). About $66.67 \%$ of students were aware that some antibiotics could cause bone marrow depression and about 33.33\% of students were not aware that some antibiotics could cause bone marrow depression (Figure 6). About 52.94\% of students were aware that the aceclofenac may induce bone marrow suppression and about $47.06 \%$ of students were not aware that the aceclofenac may induce bone marrow suppression(Figure 7).

About $60.68 \%$ of the students were aware of the complications that may take place due to bone marrow depression and about $39.22 \%$ of the students were not aware of the complications that may take place due to bone marrow depression.(Figure 8). About $84.31 \%$ of the students were aware that the bone marrow depression may lead to lack of immunity and $15.69 \%$ of the students were not aware that the bone marrow depression may lead to lack of immunity (Figure 9). About $76.47 \%$ of the students were aware that risk of infection increases in patients with bone marrow suppression and about $23.53 \%$ of the students were not aware that risk of infection increases in patients with bone marrow suppression (Figure 10)

About 54.9\% of the students were aware of the clinical features that present along with bone marrow depressions and about $45.1 \%$ of the students were not aware of the clinical features that present along with bone marrow depressions.(Figure 11). About 39.22\% of the students were aware of the treatment to be given to patients with 
bone marrow depression and $60.78 \%$ of the students were not aware of the treatment to be given to patients with bone marrow depression(Figure 12). About $78.43 \%$ of the students were aware that bone marrow suppression may lead to life threatening conditions and $21.57 \%$ of the students were not aware that bone marrow suppression may lead to life threatening conditions.(Figure 13). We know that bone marrow depression may lead to various complications and thus handling the drugs which induce the bone marrow depression must be dealt carefully. (Masamoto et al., 2016)

Our study was carried out with the aim of appraising the attitude and awareness of dentists toward the knowledge on bone marrow depressors and bone marrow depression and suggest alternative measures to overcome the same. (Kulasekararaj, Mufti and Marsh, 2013) We can observe that the students were aware of bone marrow depression. And the students also had proper knowledge about the bone marrow depressions and its complications.

Figure 1: Pie chart depicting the distribution of year of study of the dental students participating in the survey. Blue colour indicates 1st year students (27.45). Green colour indicates 2nd year students (25.49\%). Yellow colour indicates 3rd year students (24.59\%). Purple colour indicates 4 th year students (21.57\%).

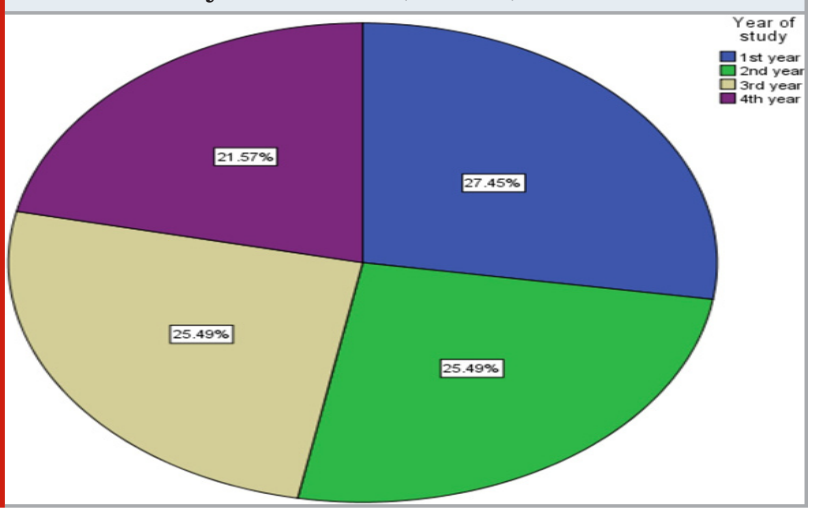

Figure 2: Pie chart depicting the awareness of importance of bone marrow among the dental students participated in the survey. Blue colour indicates students who were aware of importance of bone marrow(84.31\%) Green colour indicates students who were not aware of importance of bone marrow (15.69\%).

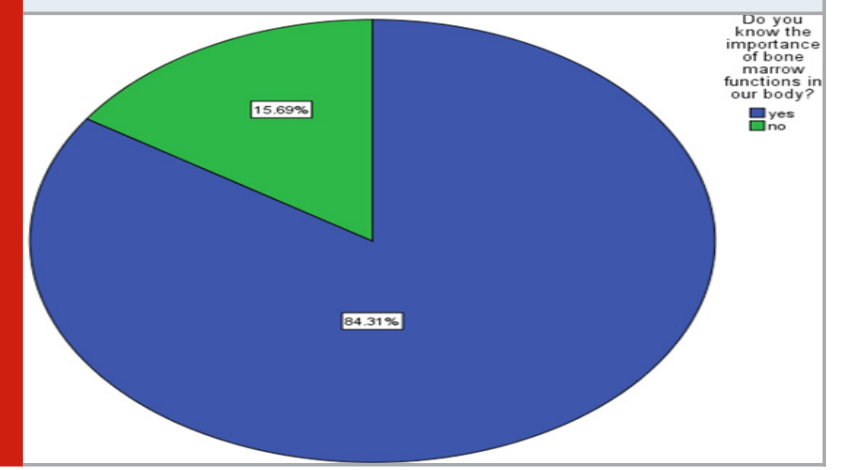

Figure 3: Pie chart depicting the awareness of bone marrow depression among the dental students participated in the survey. Blue colour indicates students who were aware of bone marrow depression (68.63\%). Green colour indicates students who were not aware of bone marrow depression (31.37\%).

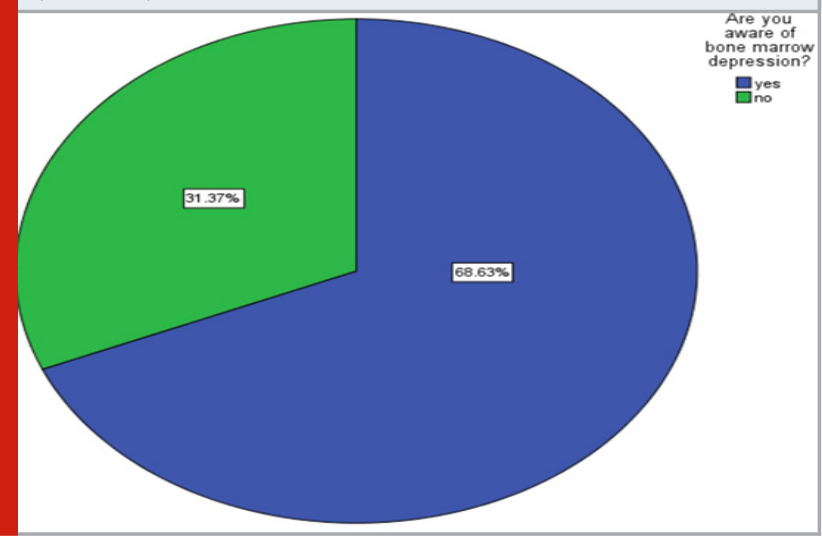

Figure 4: Pie chart depicting the awareness that certain drugs that can cause bone marrow depression among the dental students participated in the survey. Blue colour indicates students who were aware of certain drugs that can cause bone marrow depression (66.67\%). Green colour indicates students who were not aware that certain drugs that can cause bone marrow depression (33.33\%).

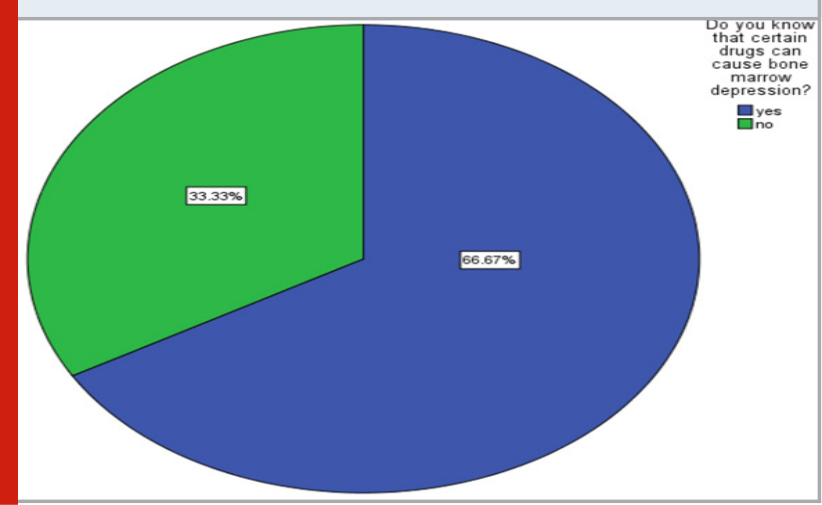

Figure 5:Pie chart depicting the awareness that NSAIDS can induce bone marrow depression among the dental students participated in the survey. Blue colour indicates students who were aware that NSAIDS can induce bone marrow depression (52.94\%). Green colour indicates students who were not aware that NSAIDS can induce bone marrow depression $(47.06 \%)$.

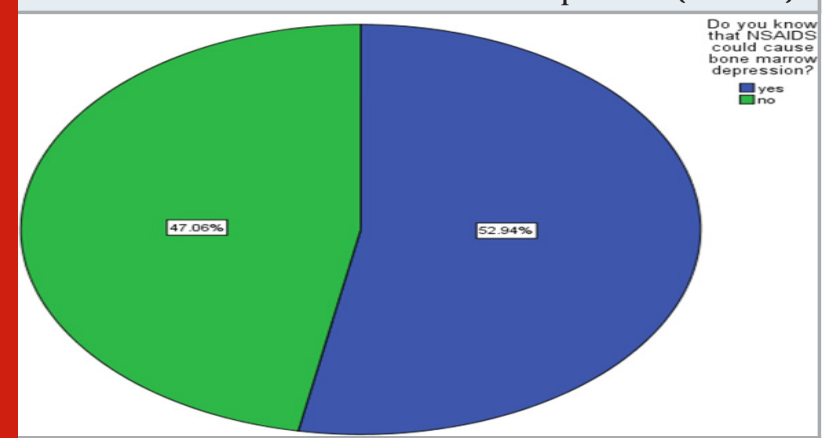


Figure 6: Pie chart depicting the awareness that antibiotics can cause bone marrow depression among the dental students participated in the survey. Blue colour indicates students who were aware that antibiotics can cause bone marrow depression (66.67\%). Green colour indicates students who were not aware that antibiotics can cause bone marrow depression (33.33\%)

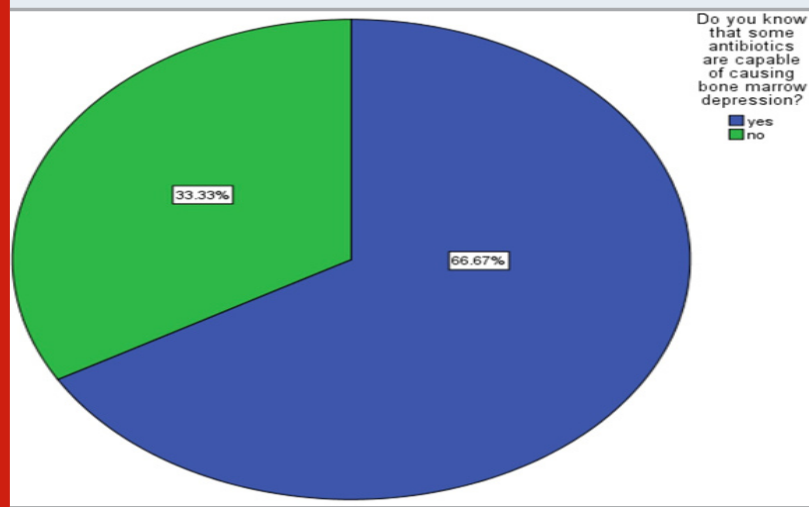

Figure 7: Pie chart depicting the awareness that aceclofenac bone marrow depression among the dental students participated in the survey. Blue colour indicates students who were aware that aceclofenac bone marrow depression (52.94\%). Green colour indicates students who were not aware that aceclofenac bone marrow depression $(47.06 \%)$

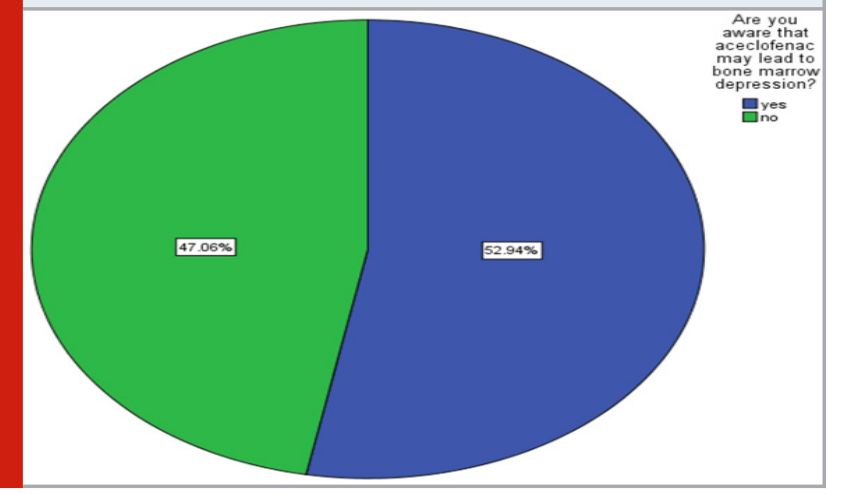

Figure 8: Pie chart depicting the awareness on complications caused by bone marrow depression among the dental students participated in the survey. Blue colour indicates students who were aware of complications caused by bone marrow depression $(39.22 \%)$. Green colour indicates students who were not aware on complications caused by bone marrow depression (60.78\%)

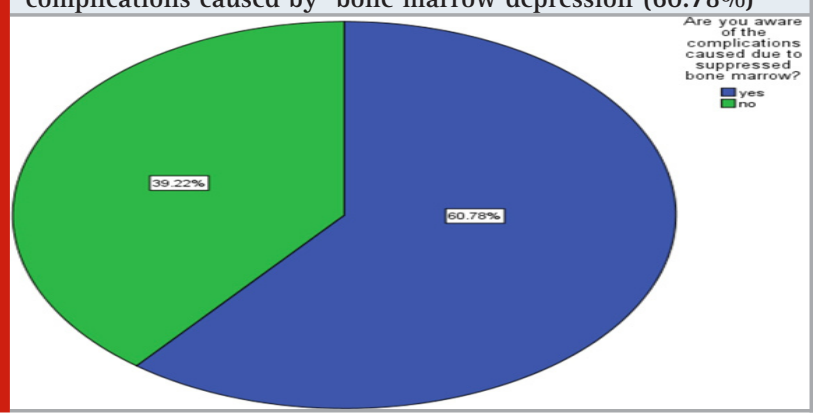

Figure 9: Pie chart depicting the awareness on bone marrow depression can cause lack of immunity among the dental students participated in the survey. Blue colour indicates students who were aware of bone marrow depression can cause lack of immunity (15.69\%). Green colour indicates students who were not aware on bone marrow depression can cause lack of immunity (84.31\%)

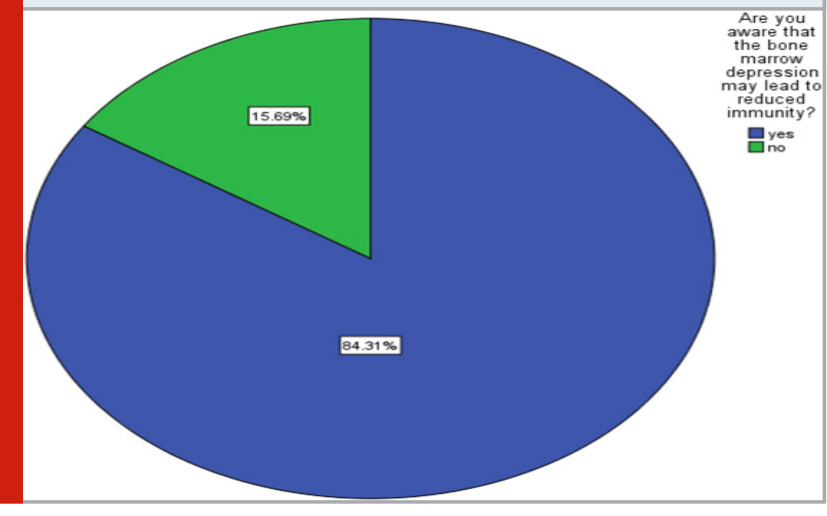

Figure 10: Pie chart depicting the awareness of patients with bone marrow depression are prone to high risk of infections among the dental students participated in the survey. Blue colour indicates students who were aware of patients with bone marrow depression are prone to high risk of infections(76.47\%). Green colour indicates students who were not aware of patients with bone marrow depression are prone to high risk of infections (23.54\%)

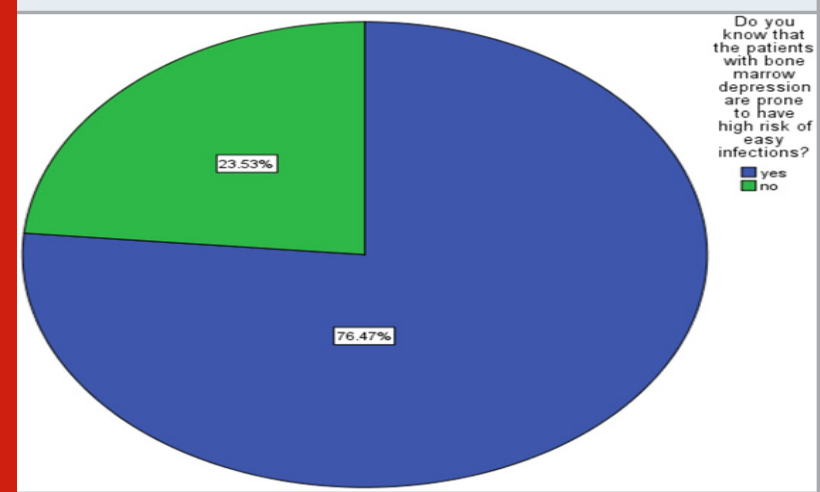

Figure 11: Pie chart depicting the awareness of clinical features seen in bone marrow depression among the dental students participated in the survey. Blue colour indicates students who were aware of clinical features seen in bone marrow depression (54.9\%). Green colour indicates students who were not aware of clinical features seen in bone marrow depression (45.1\%)

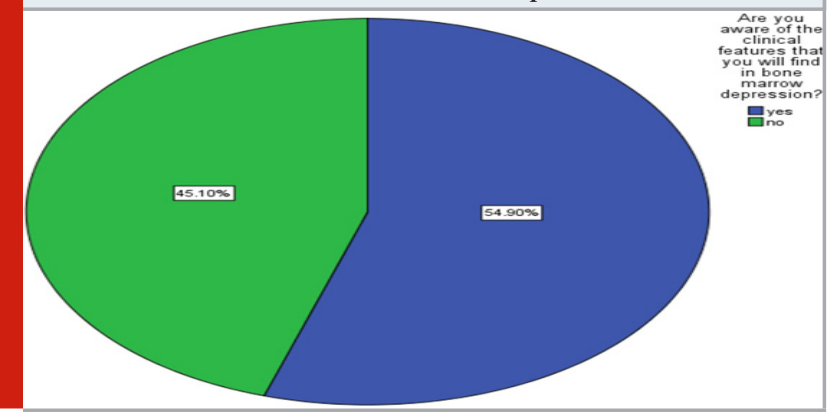


Figure 12: Pie chart depicting the awareness of treatment for bone marrow depression among the dental students participated in the survey. Blue colour indicates students who were aware of treatment for bone marrow depression (39.2\%). Green colour indicates students who were not aware of treatment for bone marrow depression $(60.78 \%)$

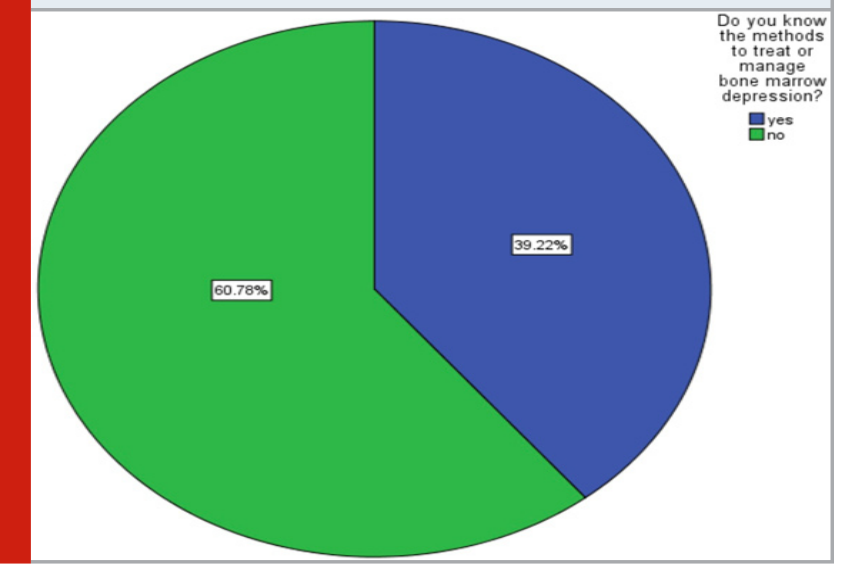

Figure 13: Pie chart depicting the awareness that bone marrow depression can lead to life threatening conditions among the dental students participated in the survey. Blue colour indicates students who were aware that bone marrow depression can lead to life threatening conditions (78.43). Green colour indicates students who were not aware that bone marrow depression can lead to life threatening conditions (21.57\%)

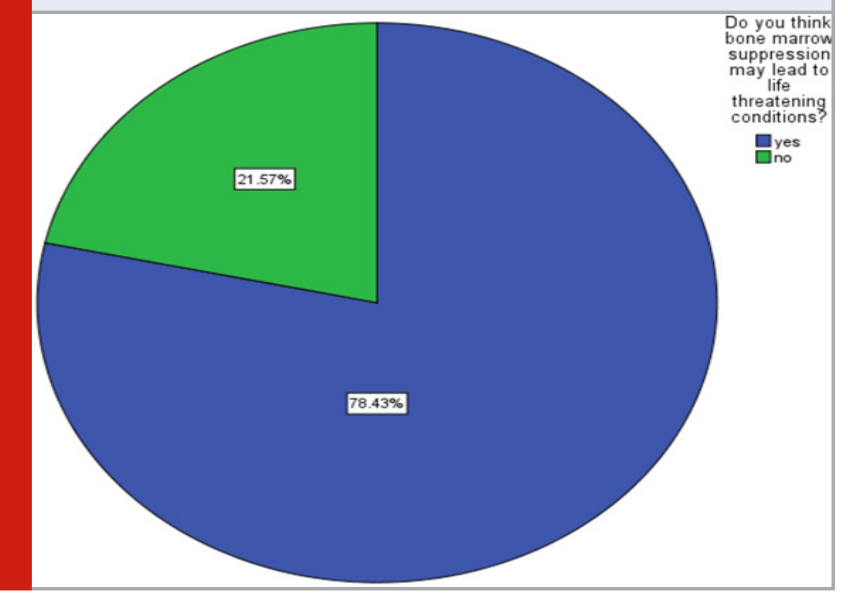

\section{CONCLUSION}

This survey aims in creating awareness among dental students about bone marrow depressors. It also creates awareness about Complications of bone marrow depression. From the results of the survey it is clear that most of the dental students were well aware of bone marrow depressors and also had proper knowledge about the bone marrow depressions and its complications.

\section{ACKNOWLEDGEMENTS}

The author would like to thank the study participants for their participation and kind cooperation throughout the study.

Conflict of Interest: The authors declare that there were no conflicts of interest in the present study.

\section{REFERENCES}

Antman, K. S. et al. (1988) 'Effect of recombinant human granulocyte-macrophage colony-stimulating factor on chemotherapy-induced myelosuppression', The New England journal of medicine, 319(10), pp. 593-598.

Armijo, J. A. et al. (1977) 'CARDIOVASCULAR EFFECTS OF NALOXONE IN RATS', Abstracts, p. 46. doi: 10.1016/ b978-0-08-021308-8.50107-1.

Brown, C. H. and Carbone, P. P. (1970) 'IN-VITRO ASSAY OF BONE MARROW SUPRESSION INDUCED BY ANTITUMOR DRUGS IN MICE', in PROCEEDINGS OF THE AMERICAN ASSOCIATION FOR CANCER RESEARCH. AMER ASSOC CANCER RESEARCH PO BOX 11806, BIRMINGHAM, AL 35202, p. 12.

Friberg, L. E. et al. (2002) 'Model of chemotherapyinduced myelosuppression with parameter consistency across drugs', Journal of clinical oncology: official journal of the American Society of Clinical Oncology, 20(24), pp. 4713-4721.

Graumlich, J. F. (2001) 'Preventing gastrointestinal complications of NSAIDs. Risk factors, recent advances, and latest strategies', Postgraduate medicine, 109(5), pp. 117-20, 123-8.

Hirbe, A. C. et al. (2007) ‘Granulocyte colony-stimulating factor enhances bone tumor growth in mice in an osteoclast-dependent manner', Blood, 109(8), pp. 3424-3431.

Inman, W. H. (1977) 'Study of fatal bone marrow depression with special reference to phenylbutazone and oxyphenbutazone', British medical journal, 1(6075), pp. 1500-1505.

Kulasekararaj, A. G., Mufti, G. J. and Marsh, J. C. W. (2013) 'Bone marrow failure - causes and complications', Medicine, pp. 257-260. doi: 10.1016/j. mpmed.2013.03.009.

Langdon, A., Crook, N. and Dantas, G. (2016) 'The effects of antibiotics on the microbiome throughout development and alternative approaches for therapeutic modulation', Genome medicine, 8(1), p. 39.

Masamoto, Y. et al. (2016) 'Adiponectin Enhances Antibacterial Activity of Hematopoietic Cells by Suppressing Bone Marrow Inflammation', Immunity, 44(6), pp. 1422-1433.

Nicholson-Weller, A., Spicer, D. B. and Austen, K. F. (1985) 'Deficiency of the complement regulatory protein, decay-accelerating factor, on membranes of granulocytes, monocytes, and platelets in paroxysmal nocturnal hemoglobinuria', The New England journal of 
medicine. Mass Medical Soc, 312(17), pp. 1091-1097. d'Onofrio, G. and Zini, G. (eds) (2014) 'Blood and Bone Marrow Cells', in Morphology of Blood Disorders. Oxford, UK: John Wiley \& Sons, Ltd (CLSI document H20-A2), pp. 1-87.

Poveda Roda, R. et al. (2007) 'Use of nonsteroidal antiinflammatory drugs in dental practice. A review', Medicina oral, patologia oral y cirugia bucal, 12(1), pp. E10-8.

Punjabi, C. J., Moore, M. A. S. and Ralph, P. (1983)
'Suppression of natural killer activity in human blood and bone marrow cultures by bone marrow-adherent OKM1-positive cells', Cellular Immunology, pp. 13-22. doi: 10.1016/0008-8749(83)90002-3.

Snow, J. L. and Gibson, L. E. (1995) 'The role of genetic variation in thiopurine methyltransferase activity and the efficacy and/or side effects of azathioprine therapy in dermatologic patients', Archives of dermatology, 131(2), pp. 193-197.

Weeks, J. C. et al. (2012) 'Patients' expectations about effects of chemotherapy for advanced cancer', The New England journal of medicine, 367(17), pp. 1616-1625. 